\title{
Threshold of intelligibility/comprehensibility of rapid connected speech: Method and instrumentation
}

\author{
HENRY J. de HAAN and JOHN R. SCHJELDERUP \\ U.S. Army Research Institute, Alexandria, Virginia 22333
}

\begin{abstract}
A threshold method has been developed for determination of the maximum rate of connected speech understood by an individual. The method is similar to the Békésy method for the determination of pure-tone thresholds but differs from it in that rate of speech is varied rather than intensity of a tone. Instrumentation that varies speech rate with or without pitch changes was developed and is described in some detail.
\end{abstract}

A review of the literature on rate of speech revealed that no threshold method was available for evaluating the understanding of connected speech based on variations in the rate of speech rather than variations in intensity. Consequently, a simple, direct, psychophysical method was developed that is analogous to the Békésy (1947) method for determining pure-tone loudness thresholds; however, rapidity of speech rather than intensity is varied. Rapidity increases automatically until the listener indicates, by pressing a button, that he no longer understands speech. Rapidity then decreases until the listener indicates, by releasing the button, that he understands it again. A repetition of this process, whereby the listener responds to and controls the changing rate of speech, effectively brackets the rate at which understanding fails as rapidity increases. The method assumes that the listener can perceive the point at which he no longer understands speech as it becomes more rapid.

\section{INSTRUMENTATION}

\section{General System Description}

Figure 1 is a block diagram of the system, which presents either speeded speech (speed-changing method) or compressed speech (sampling method). Speeded speech is obtained by means of a variable-speed tape recorder together with a speed-control device. Compressed speech is obtained by an AmBiChron pitch compensator (Koch,

This work was reported in part at the 27 th International Congress of Physiological Sciences, Paris, France, July 18-23, 1977. Requests for reprints should be sent to Henry J. de Haan, U.S. Army Research Institute for the Behavioral and Social Sciences, 5001 Eisenhower Avenue, Alexandria, Virginia 22333. We thank Charles Marshall for computer programming and John A. Kaspick for fabrication of the tape speed- and pitchcontrol device and for other technical assistance. The views expressed in this paper are those of the authors and do not necessarily represent those of the Department of the Army or the U.S. Army Research Institute; neither does designation of commercial products constitute official endorsement of them.
1974) in conjunction with the above equipment. The AmBiChron digitizes speech, writes this into a temporary memory, and reads from the memory at a rate slower than the writing rate, discarding a portion of what was written. The relative rates of writing and reading are such that the AmBiChron produces speech with nearly constant pitch, despite changing speeds. The error in pitch (frequency) correction of the total system is less than $3 \%$ in the speed range from normal to twice normal, but it increases progressively to $10 \%$ at 3.7 times normal speed. Since considerable pitch shift can be tolerated (at least 50\% above normal pitch, according to Garvey, 1953) before intelligibility is seriously degraded, these errors in pitch correction are not considered to be of major importance.

Both the speed of the tape recorder and the pitch compensation of the AmBiChron are remotely controlled by a laboratory-fabricated device that provides for an initial speed and various rates of acceleration and deceleration that are all adjustable by potentiometers. This device applies control voltages to the tape recorder and the AmBiChron. The voltage that determines speed is displayed on a digital voltmeter and recorded on a

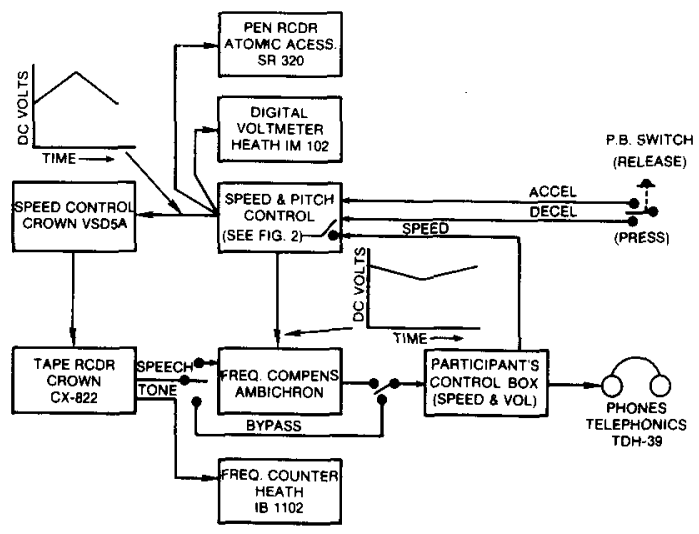

Figure 1. Block diagram of major instrumentation 
strip-chart recorder. In addition, all speech tapes have a $1,000-\mathrm{Hz}$ tone recorded on a second channel at $3.75 \mathrm{in} . / \mathrm{sec}$ (IPS) $(9.525 \mathrm{~cm} / \mathrm{sec})$. As tape, speed varies, the frequency, which is indicative of the momentary speed of speech, changes proportionately and can be read on a digital frequency counter.

Equipment used by the listener includes a control box that allows the intensity and rate of speech to be set by potentiometers (the rate potentiometer is inactivated for automatic threshold determinations), a pair of headphones, and an audiometer switch used to select either acceleration or deceleration. Prior to threshold determinations, rates of acceleration and deceleration are set by the experimenter.

\section{Tape Speed- and Pitch-Control Device}

General. The circuitry of the control device is shown in Figure 2 and a parts list is given in Table 1. The unit is basically a voltage ramp generator (Al and associated components) and an adder (IC1 and components) that combines the ramp voltage with a preset starting-level voltage. The output of IC1 connects to the tape-recorder speed control, with $+2.5 \mathrm{~V}$ corresponding to 3.75 IPS and $+10.0 \mathrm{~V}$ corresponding to 15 IPS. Since the input to the AmBiChron voltage-controlled oscillator (VCO) requires a simultaneous but different ramp with the range of +13.46 to $+12.41 \mathrm{~V}$ to maintain the voice pitch at normal for the corresponding speed range of 3.75 to 7.5 IPS, the ramp obtained at IC1 is converted to another ramp having an opposite slope, smaller range, and shifted level. This is effected by IC2 and components, and the output of this stage connects to the VCO of the AmBiChron.

Circuit details. Al is the basic ramp generator and is configured as an integrator where $\mathrm{C} 1, \mathrm{C} 2$ combination is charged through $\mathrm{R} 6, \mathrm{R} 7$ or $\mathrm{R} 8, \mathrm{R} 9$ (selected by S4) by a positive or negative voltage (selected by $\mathrm{S} 1$ ). $\mathrm{S} 2$ allows either the experimenter (by $\mathrm{S} 1$ ) or the listener (by S7) to select a positive- or negative-going ramp. $\mathrm{C} 1$ and $\mathrm{C} 2$ were selected for low leakage to minimize

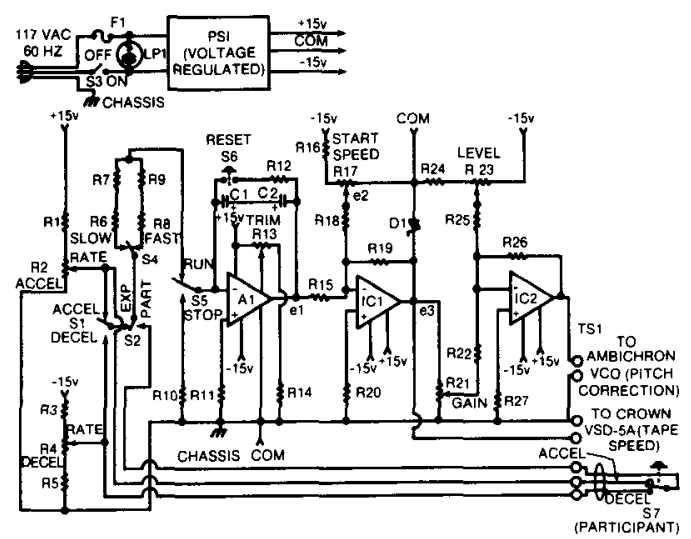

Figure 2. Electrical schematic of tape speed- and pitchcontrol device.
Table 1

Parts List for Tape Speed- and Pitch-Control Unit

\begin{tabular}{ll}
\hline A1 & $\begin{array}{l}\text { Discrete operational amplifier, Analog Devices } \\
118 \mathrm{~A} .^{*}\end{array}$ \\
C1,C2 & Capacitor, $10 \mathrm{microF} / 25 \mathrm{WV}$ dc, Sprague TE- \\
& 1204. \\
D1 & Diode, $1 \mathrm{~N} 5856 \mathrm{~A}, 10-\mathrm{V}$ Zener, $500 \mathrm{~mW}$. \\
F1 & Fuse, Littelfuse $3 \mathrm{AG} 1 / 4 \mathrm{~A}, 250 \mathrm{~V}$.
\end{tabular}

IC1,IC2 Integrated circuit, operational amplifier;

Calectro K4-590 (equiv 741).

LP1 Lamp, Neon, Industrial Devices 2150A.

PS1 Power supply, $+15 \mathrm{~V}$, Com, $-15 \mathrm{~V}, 25 \mathrm{~mA}$,

Semiconductor Circuits SQ2-15.30.**

R1,R3 Resistor, 10 kohms. $\dagger$

R2,R4,R17 Resistor, 10 kohms, one-turn potentiometer, Centralab F2-10K.

R6 Resistor, $120 \mathrm{ohm}$.

R6 Resistor, 10 megohm.

R7 Resistor, 3.3 megohm.

R8,R11 Resistor, 220 kohm.

R9 Resistor, $18 \mathrm{kohm}$.

R10 Resistor, 12 megohm.

R12 Resistor, 100 ohm.

R13,R21,R23 Resistor, $10 \mathrm{kohm}$, multiturn trimming potentiometer, Allen-Bradley RP103U, or Bourns 3006.

R14 Resistor, 100 kohm.

R15,R18,R19,

R22,R25,R26 Resistor, 1 megohm.

R16 Resistor, $12 \mathrm{kohm}$.

R20,R27 Resistor, $330 \mathrm{kohm}$.

R24 Resistor, 22 kohm.

S1,S2,S4,S5 Switch SPDT, ALCO MST-105.

S3

Switch, SPST, $125 \mathrm{~V}$ ac, $3 \mathrm{~A}$, Cutler-Hammer 8280.

S6 Switch, N/O pushbutton, Grayhill 10-9.

S7 Switch, pushbutton, nonlocking, Switchcraft EP 903, or audiometer switch, Grason-Stadler E800-6.

*Analog Devices, Inc., P.O. Box 280, Norwood, Massachusetts 02062. **Semiconductor Circuits, Inc., 306G River Street, Haverhill, Massachusetts $01830 . \quad$ tAll fixed resistors have . 5-W 5\% tolerance.

output-voltage drift at $\mathrm{Al}$ when in the stop mode (S5 set to STOP). When set to STOP, both the inverting and noninverting inputs of $\mathrm{Al}$ are at the same potential (common) through R10 and R11, integration ceases, and the ramp voltage at $A 1$ output holds a steady value. To set up initial ramp level, the RESET pushbutton switch $\mathrm{S} 6$ is pressed, which rapidly discharges $\mathrm{Cl}$ or $\mathrm{C} 2$, and $\mathrm{A} 1$ output voltage goes very nearly to zero. R12 limits the discharge current to a value safe for S6. TRIM potentiometer R13 is set once, so that Al has as little output drift as possible when the integrator is in the STOP mode. At that time, A1 output will not be exactly at zero, but this is inconsequential, because START SPEED potentiometer R17 is never set to obtain a starting speed near zero. Al is Analog Devices Type 118A, which has a lower rated input-bias current than the common $741 \mathrm{IC}$; perhaps the latter would function as satisfactorily here.

IC1 is configured as an inverting adder that combines 
the ramp voltage from $A 1$ output through $\mathrm{R} 15$ with the adjustable starting-speed voltage through R18. Since feedback resistor R19 and adding resistors R15 and $\mathrm{R} 18$ all have the same value, $\mathrm{e} 3=-(\mathrm{e} 1+\mathrm{e} 2)$. D1 limits IC1 output to $+10 \mathrm{~V}$, corresponding to a speed factor of $4: 1$, beyond which the AmBiChron did not function properly. R20 is $1 / 3$ megohm to match the combined effective resistance of $\mathrm{R} 15, \mathrm{R} 18$, and $\mathrm{R} 19$, in order to equalize bias currents in both inputs of $\mathrm{ICl}$, thereby minimizing spurious shifts in output hevels.

IC2 is configured as an inverting adder. By means of GAIN potentiometer R21, a $2.5-\mathrm{V}$ change in the output of $\mathrm{ICl}$ is reduced to a $1.05-\mathrm{V}$ change and fed to the inverting input of IC2 through R22. By means of LEVEL potentiometer $R 23$, the appropriate voltage is fed through $\mathrm{R} 25$ to the inverting input of IC2, so that the output of IC2 can be set to $+13.46 \mathrm{~V}$ when the output of IC1 is $+2.5 \mathrm{~V}$. R27 has a function similar to that of R20 discussed above. Thus, when IC1 output ramp goes from +2.5 to $+5.0 \mathrm{~V}$, the tape transport goes from 3.75 to $7.5 \mathrm{IPS}$, and speech frequencies go from normal to twice normal at the tape-recorder output. Simultaneously, the IC2 output ramp goes from +13.46 to $+12.41 \mathrm{~V}$, which effects a frequency division in the $\mathrm{AmBiChron}$ in the range 1.0 to 2.0. Hence, speech has normal pitch regardless of tape speed.

Calibration. The following procedure adjusts speed and pitch ramps for coordinated operation: (1) Lift R25 where it joins potentiometer R23 LEVEL control and connect lifted lead to common. (2) Set S5 to STOP, press S6 RESET, set R17 START SPEED so that $\mathrm{e} 3$ is $+2.50 \mathrm{~V}$, and adjust R21 GAIN control so that IC2 output is approximately $-1.05 \mathrm{~V}$. (3) Set R17 START SPEED so that $\mathrm{e} 3$ is $+5.00 \mathrm{~V}$ and note output of IC2. This should be close to $-2.10 \mathrm{~V}$. (4) If difference in output between Steps 2 and 3 is not exactly $1.05 \mathrm{~V}$, it will be necessary to repeat Steps 2 and 3. (5) Restore R25 to original connection. (6) Set R17 START SPEED so that e3 is $+5.00 \mathrm{~V}$. Adjust R23 LEVEL control so that IC2 output is $+12.41 \mathrm{~V}$. Now set R17 START SPEED so that $\mathrm{e} 3$ is $+2.50 \mathrm{~V}$; IC2 output should be $+13.46 \mathrm{~V}$.

\section{EVALUATION OF THE METHOD}

Two experiments have been performed to evaluate the method and to determine whether thresholds are related to intelligibility and comprehension of speech (de Haan, 1977). The first compared thresholds of two types of rapid speech, speeded and compressed. Higher thresholds were found for compressed speech than for speeded speech, which supports the hypothesis that the thresholds for compressed speech are limited mainly by the rate at which the listener is able to process verbal information, while those for speeded speech are additionally limited by reduced intelligibility due to pitch distortion. Rate of acceleration-deceleration had

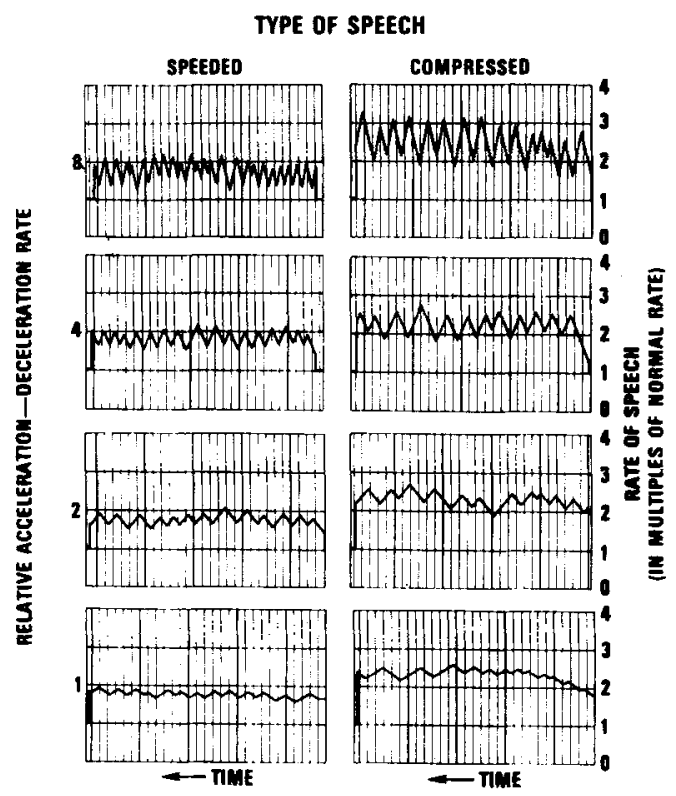

Figure 3. Record of eight threshold determinations on a single individual. A relative acceleration-deceleration rate of 1 indicates that the rate of speech changes from normal to twice normal (and vice versa) in $60 \mathrm{sec}$. Other values represent proportionately faster rates.

little effect on thresholds, although it did have a pronounced effect on the word-rate swings as the listener tracked his threshold. Figure 3 shows an individual performance record for both types of speech.

The second experiment sought to determine the relationship of the threshold for compressed speech to traditional comprehension measures. The correlation between threshold values and comprehension test scores was generally low for passages at several rates of speech (from 1.5 to 3.0 times normal rate). This does not support the hypothesis that the threshold is a measure of comprehension per se, although it does not preclude the possibility that the threshold may be a measure of comprehensibility in the sense that the term is used by Deese and his students (Schwartz, Sparkman, \& Deese, 1970), that is, the perception of the feasibility of comprehension.

Thresholds were determined for 3-min periods in the above work, using four thresholds per listener to increase reliability. An estimate of the reliability of the threshold was obtained from intercorrelations of the various conditions in the first experiment. Correlations between the two types of rapid speech at each of the four rates of acceleration-deceleration yielded the following coefficients: $.77, .72, .84$, and .75 . An average value of .77 was obtained for the 3 -min trials by means of Fisher's r-to-z transformation. Since four thresholds for each type of speech were determined, an estimate of reliability for $12 \mathrm{~min}$ of data may be obtained by applying the Spearman-Brown formula for quadruple length. This yields a correlation coefficient of .93 . 


\section{AUTOMATED INSTRUMENTATION}

After the two experiments had been completed, a more automated version of the above instrumentation was developed. An ADS 1800E computer (Automated Data Systems) controls the sequencing and timing of a group of relays with the following functions: (1) select acceleration rate (one of four), (2) select deceleration rate (one of four), (3) reset to initial rate, (4) audio "blanking," (5) start/stop tape recorder and pen recorder. Contacts of four relays select preset acceleration and deceleration potentiometers instead of R1, R2, R3, R4, R5 of Figure 2. The contacts of a fifth relay control an existing relay that has: (1) a set of N.O. contacts wired to the RESET pushbutton S6, (2) another set wired in series with the paper drive power of the pen recorder, and (3) a third set wired in series with the ramp voltage to the recorder variable-speed control unit. A sixth relay opens the line to the listener's earphones during high-speed tape-search periods.

A very desirable feature of this version is the use of the computer as a frequency counter. It is programmed to measure the frequencies of the tone (recorded on the second tape channel) during transitions from rising to falling and from falling to rising, and to store these values. At the end of an experimental run, the computer prints out the value of each peak and valley in terms of speed factors (e.g., 2.00 represents twice the normal rate) and produces the average of all speed factors. The latter, when multiplied by words per minute on the tape (at normal speed), yields the threshold value. The frequency printout eliminates the need for laborious hand measurement of peaks and valleys on the recorder chart; the pen recorder is used mainly as a graphic aid to the experimenter.

\section{POTENTIAL APPLICATIONS}

The threshold technique may have utility for both research and practical applications. One possible use is to evaluate central speech processing disorders (de Haan, Note 1). Other potential applications include: the determination of individual differences in speech perception rate; the evaluation of intelligibility of speech from devices that compress or synthesize speech; and the evaluation of recorded materials, including difficulty of the materials and the underlying syntactic and semantic variables.

\section{REFERENCE NOTE}

1. de Haan, H. J. Terminal threshold of understanding speech: $A$ possible tool for neuropsychology. Paper presented at the International Neuropsychology Society European Conference, St. Catherine's College, Oxford University, Oxford, England, August 1-4, 1977.

\section{REFERENCES}

BÉkÉsy, G. von. A new audiometer. Acta Otolaryngologica, $1947,35,411-422$.

DE HAAN, H. J. A speech-rate intelligibility threshold for speeded and time-compressed connected speech. Perception \& Psychophysics, 1977, 22, 366-372.

GaRVEY, W. D. The intelligibility of speeded speech. Journal of Experimental Psychology, 1953, 54, $102-108$.

KoсH, R. The AmBiChron. In S. Duker (Ed.) Time-compressed speech: An anthology and bibliography. Metuchen, N.J: Scarecrow Press, 1974.

Schwartz, D., Sparkman, J. P., \& Deese, J. The process of understanding and judgments of comprehensibility. Journal of Verbal Learning and Verbal Behavior, 1970, 9, 87-93.

(Received for publication February 21, 1978; revision accepted August 18, 1978.) 